\title{
Studies on Nitration of Phenol over Solid Acid Catalyst
}

\author{
Lipika Das ${ }^{1}$, Koushik Guha Biswas ${ }^{2 *}$ and Jayanta Kumar Basu ${ }^{3}$ \\ ${ }^{1}$ Department of Chemical Engineering, Haldia Institute of Technology, India \\ ${ }^{2}$ Department of Chemical Engineering, Rajiv Gandhi Institute of Petroleum Technology, India \\ ${ }^{3}$ Department of Chemical Engineering, Indian Institute of Technology, India
}

*Corresponding author: Koushik Guha Biswas, Department of Chemical Engineering, Rajiv Gandhi Institute of Petroleum Technology, Amethi, Uttar Pradesh, Pin-229304 India.

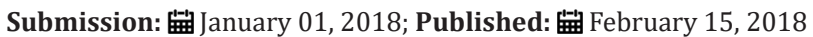

\section{Graphical Abstract}

Phenol is nitrated selectively by dilute nitric acid over alumina and a remarkable ortho-selectivity is observed in liquid phase nitration.

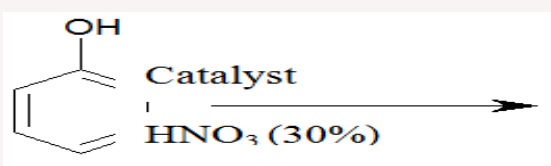

Phenol<smiles>O=[N+]([O-])c1ccccc1O</smiles>

O-nitrophenol<smiles>O=[N+]([O-])c1ccc(O)cc1</smiles>

P-nitrophenol<smiles>O=C1C=CC(=O)C=C1</smiles>

Benzoquinone (Oxidized product)

Highlights

i. The solid acid catalyst (Gamma-alumina) was prepared by control precipitation method.

ii. Phenol was selectively nitrated in liquid phase using dilute nitric acid (30\%) in presence $\gamma$-alumina.

iii. The nitration reaction was carried out at room temperature and produce ortho-nitrophenol.

iv. The activation energy of the reaction was $11.272 \mathrm{KJ} / \mathrm{mol}$.

v. The kinetic study was also observed.

Abstract

Phenol was selectively nitrated in liquid phase to produce ortho-nitrophenol using dilute nitric acid (30\%) at room temperature in presence of hydrochloric acid treated $\gamma$-alumina. Initially $\mathrm{Al}\left(\mathrm{NO}_{3}\right)$ and $\mathrm{NH}_{4} \mathrm{HCO}_{3}$ were reacted to prepare $\mathrm{Al}(\mathrm{OH})_{3}$ which on successive calcinations at $550{ }^{\circ} \mathrm{C}$ for $5 \mathrm{~h}$ produce $\gamma$-alumina. The $\gamma$-alumina was characterized by BET, XRD, SEM and $\mathrm{NH}_{3}$-TPD analysis. The XRD profile confirmed the crystalline structure of the solid acid catalyst $\gamma$-alumina. The $\mathrm{NH}_{3}$-TPD analysis showed the development of lewis acidity on the surface of hydrochloric acid treated $\gamma$-alumina. The effects of various parameters such as concentration of reactants, types of catalyst, weight of the catalyst, solvent, temperature and time of reaction have been studied. The kinetics of the reaction was also investigated.

Keywords: Gamma alumina catalyst; Nitration reaction; Ortho-nitrophenol; Rate constant

\section{Introduction}

Nitration of aromatic substances has greatindustrialimportance because nitro-aromatics are extensively used as raw material for manufacturing dyes, pharmaceuticals, perfumes and plastics [1,2]. It is found from the previous study that the nitration of phenol using a mixture of nitric and sulfuric acid gives 2-nitrophenol and 4-nitrophenol in a ratio of 1.42 [1]. The limitation of this process lies in the use of corrosive liquid mixture of nitric and sulfuric acid which produce large amounts of wastes. The other problems are the chance of over nitration, poor selectivity and high cost of the process etc. [3]. To overcome these difficulties a new and simpler technique such as solid acid nitration should be employed. In the solid acid nitration process the solid acid is used as a catalyst instead of sulfuric acid to produce nitronium ion. It is found from various literature that the nitration of phenol was carried out using different catalysts such as hydrous zirconia [4], tetra butyl ammonium bromide [5,6], sulfated titania [7], $\mathrm{N}_{2} \mathrm{O}_{5}-\mathrm{ClNO}_{2}$ [8], p-Toluenesulfonic acid [9], ZSM-5 Zeolite [10], sulfated titania [11] and $\mathrm{SnO}_{2}$ [12]. The selectivity of the product is increased by using proper solvent with solid acid catalyst. In the last few years various nitration procedures have been performed using different aromatic solvents such as N-nitropyrazole/ $\mathrm{BF}_{3}, \mathrm{Zn}\left(\mathrm{NO}_{3}\right)_{2} \bullet 6 \mathrm{H}_{2} \mathrm{O} / 2,4,6$ trichloro-1,3,5-triazine in acetonitrile [13] and ionic liquid [14]. 
On the other hand alumina has extensive applications in organic reactions, either as an active participant or as an inert support. Alumina-based solid acid catalysts are potentially attractive due to the easy removability of substrate-product and easy recycling. The ortho-nitrophenol which is a major product of nitration reaction used for synthesis of valuable compounds. Some of these methods have contributed significantly for enhancing the scope of nitration reaction but very little work has been done on the region selectivity of phenol over alumina as a catalyst [15].

In the present work a suitable solid acid catalyst was investigated for nitration of phenol to ortho-nitrophenol. The region selectivity of phenol was studied using dilute nitric acid as nitrating agent over alumina as solid acid catalyst. The selectivity of the reaction is increased by using carbon tetra chloride as a solvent with the catalyst. The effects of different process parameters such as type of catalyst, weight of catalyst, time, temperature, reactant concentration, type of solvents and $\mathrm{HCl}$ treatment were observed. The kinetic study was also performed.

\section{Materials and Methods}

\section{Materials}

Aluminium nitrate $\left(\mathrm{Al}\left(\mathrm{NO}_{3}\right)_{3}, 9 \mathrm{H}_{2} \mathrm{O}, 95 \%\right)$ of $\mathrm{GR}$ grade ammonium bi carbonate $\left(\mathrm{NH}_{4} \mathrm{HCO}_{3}, 98 \%\right)$ of GR grade, acetone $\left(\mathrm{CH}_{3} \mathrm{COCH}_{3}\right)$, carbon tetrachloride $\left(\mathrm{CCl}_{4}\right)$, methanol, sodium hydroxide $(\mathrm{NaOH})$ and phenol $\left(\mathrm{C}_{6} \mathrm{H}_{5} \mathrm{OH}\right)$ were procured from Merck (India) Ltd., Mumbai, India. Ethanol $\left(\mathrm{C}_{2} \mathrm{H}_{5} \mathrm{OH}\right)$ was supplied by Jiangsu Huaxi International Trade Co. Ltd., China and nitric acid $\left(\mathrm{HNO}_{3}\right)$ was procured from S. d. fine Chem Ltd. Hydrochloric Acid ( $\mathrm{HCl})$ was procured from Sarabhai M Chemicals.

\section{Catalyst preparation}

Gamma alumina was prepared using control precipitation technique. Initially $15.42 \mathrm{gm}$ of ammonium bicarbonate and $40 \mathrm{gm}$ of aluminum nitrate was dissolved separately in $600 \mathrm{ml}$ of deionized water. The solutions were added drop wise to $400 \mathrm{ml}$ deionized water in a reaction vessel (Eq. 1). The reaction vessel was placed in a water bath and the temperature was maintained at 70 ${ }^{\circ} \mathrm{C}$. The mixture was stirred for 30 minutes. The $\mathrm{pH}$ of the solution was adjusted by using $\mathrm{HNO}_{3}$ or $\mathrm{NaOH}$ to precipitate $\mathrm{Al}$ cations in the form of hydroxide (Eq. 2). Then the precipitate was aged at $70{ }^{\circ} \mathrm{C}$ for 3 hours and washed thoroughly with warm de-ionized water, ethanol followed by acetone to avoid contamination of $\mathrm{Na}$ ions. The washed material was air-dried at $120{ }^{\circ} \mathrm{C}$ for 12 hours. After air drying the precipitate was calcined in a programmable furnace at $550{ }^{\circ} \mathrm{C}$ for 5 hours. The various reactions involved in the preparation of alumina are given bellow.

$$
\begin{aligned}
& \mathrm{NH}_{4} \mathrm{HCO}_{3}+\mathrm{HOH} \rightarrow \mathrm{NH}_{4} \mathrm{OH}+\mathrm{H}_{2} \mathrm{O}+\mathrm{CO}_{2}(1) \\
& \mathrm{Al}\left(\mathrm{NO}_{3}\right)_{3}+3 \mathrm{NH}_{4} \mathrm{OH} \rightarrow \mathrm{Al}(\mathrm{OH})_{3} \downarrow+3 \mathrm{NH}_{4} \mathrm{NO}_{3}(2) \\
& \mathrm{Al}(\mathrm{OH})_{3} \rightarrow \mathrm{AlOOH} \downarrow+\mathrm{H}_{2} \mathrm{O}(3) \\
& \mathrm{AlOOH} \rightarrow \mathrm{Al}_{2} \mathrm{O}_{3}+\mathrm{H}_{2} \mathrm{O}(4)
\end{aligned}
$$

\section{The catalyst activation}

Alumina powder was activated using hydrochloric acid $(\mathrm{HCl})$. It was soaked for 30 hours in de-ionized water and different percentages of $\mathrm{HCl}$ at room temperature. Then the material washed thoroughly with distilled water and dried overnight at $120{ }^{\circ} \mathrm{C}$. The sample was then calcined at $350{ }^{\circ} \mathrm{C}$ for 2 hours in presence of oxygen.

\section{Catalyst characterization}

The characterization of the catalyst was done by using the BET surface area analyzer (AUTOSORB-1C- USA), scanning electron microscope (Hitachi model SU-70), chemical composition of the catalyst, $\mathrm{NH}_{3}$-TPD (Quantachrome Instruments) and $\mathrm{x}$-ray diffractometer (Philips PW183).

\section{Reaction procedure}

Nitration of phenol to orthonitro phenol was performed in a. three necked round bottom flask type glass reactor $(6.5 \mathrm{~cm}$ I.D) with a capacity of $250 \mathrm{~cm}^{3}$. The reactor was equipped with a fourleg vertical baffle $(2.0 \mathrm{~cm}$ diameter) which is located at a height of $1.5 \mathrm{~cm}$ from the bottom of the reactor. Two gram of phenol was taken in a flask containing $3 \mathrm{ml}$ carbon tetrachloride. Then $1 \mathrm{~g}$ of alumina and $4 \mathrm{ml}$ of dilute nitric acid (30\%) were added into it. The reaction mixture was stirred at room temperature for varying period of time to study the progress of the reaction. The products were analyzed by HPLC(Column -Zorabax C-18 Reverse phase, Column Length-250mm, Column Dia-4.6mm, Pump-(Perkin Elmer, series 200, Isocratic pump), Detector-(Perkin Elmer, series 200, UV/VIS Detector), Mobile Phase- 50\% Methanol / 50\% Water, Flow Rate- $1.0 \mathrm{ml} / \mathrm{min}$, Wavelength-254n).

\section{Kinetic study}

The kinetic study was performed in the same glass reactor as above. The reaction mixture was agitated for 180 minutes and samples were collected at different time intervals. The experimental data were analyzed by pseudo first and second order kinetics mechanism. Although the reaction is carried out heterogeneously, but a homogeneous reaction mechanism with a second-order kinetics is assumed to interpret the experimental data. The isothermal reaction under constant-volume conditions results in the rate equation of the following form

$$
-r_{A}=\frac{d C_{A}}{d t}=k C_{A} C_{B}
$$

Where A is limiting reactant phenol and B is excess reactant nitric acid.

After integrating equation (5) the final form is represented as equation (6).

$$
\ln \left[\frac{\left(M-X_{A}\right)}{M\left(1-X_{A}\right)}\right]=C_{A 0}(M-1) k t
$$

Where $C_{A 0}$ and $C_{B 0}$ represent the initial concentrations of reactants $\mathrm{A}$ and $\mathrm{B}$ respectively and $\mathrm{k}$ is the reaction rate constant.

$$
M=\frac{C_{B 0}}{C_{A 0}}=\text { the initial molar ratio of the reactants }
$$




\section{Arrhenius equation}

Arrhenius equation describes the effect of temperature on activation energy $E$ and the frequency factor $A$. The value of $E$ can be calculated from the rate constants at three different temperatures (T). The temperature dependency of reaction rate, $\mathrm{k}$, is given by the Arrhenius equation,

$$
\mathrm{k}=\mathrm{Ae}^{-\mathrm{E} / \mathrm{RT}}(7)
$$

The rate constant $\mathrm{k}$ can be obtained from equation (6). It is an average of values calculated at various experimental kinetic data points (i.e., reactant concentrations at various reaction times).

\section{Result and Discussion}

\section{Characterization of the prepared catalyst}

Table 1: Characteristics of different catalysts.

\begin{tabular}{|c|c|c|c|}
\hline Sample & SBET $\left(\mathbf{m}^{2} / \mathbf{g}\right)$ & Pore Volume $(\mathbf{c c} / \mathbf{g})$ & Pore Size $(\mathbf{n m})$ \\
\hline Alumina & 220 & 0.216 & 219 \\
\hline $\begin{array}{c}\text { Acid treated } \\
\text { alumina }\end{array}$ & 294.1 & 0.157 & 326 \\
\hline
\end{tabular}

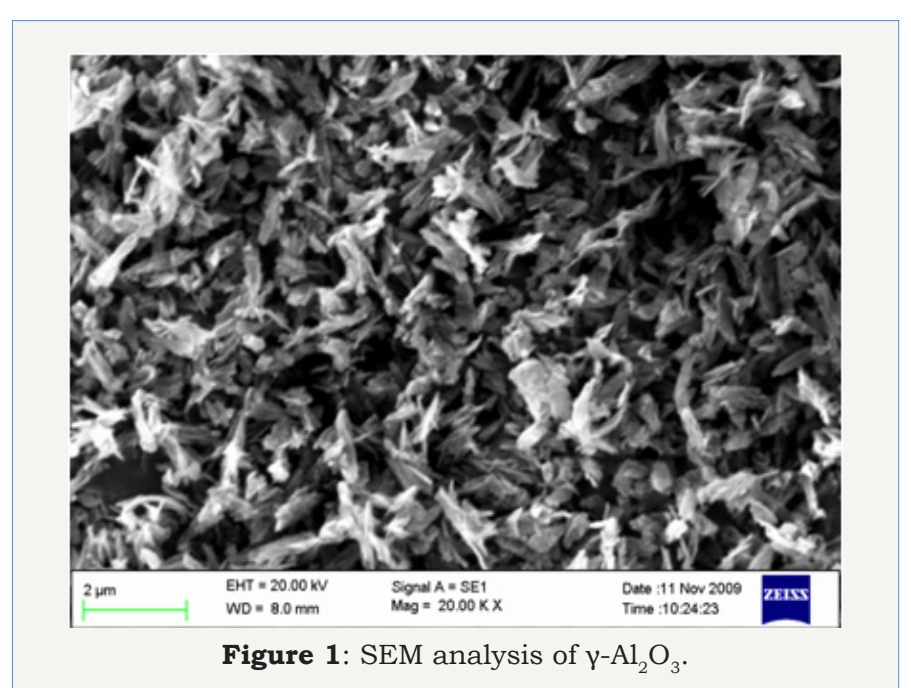

The surface area, pore volume and the average pore size of alumina and acid treated alumina were analyzed in BET surface area analyzer. The values are shown in Table 1. The scanning electron microscope (SEM) image (Figure 1) of the alumina catalyst indicates strong agglomeration of alumina particles. The scanning electron microscope (SEM) image also confirms the formation of a gamma phase $\left(\gamma-\mathrm{Al}_{2} \mathrm{O}_{3}\right)$ on alumina catalyst. Quantitative as well as qualitative composition analysis of prepared alumina was determined by EDS spectrum obtained from SEM. The elemental analysis of prepared alumina shows that it contains $59.42 \% 0$ and $40.58 \% \mathrm{Al}$. The NH3-TPD spectra of the $\gamma$-alumina powder and acid treated $\gamma$-alumina powder is shown in Figure 2. It is seen that the TPD spectra (Figure 2) of the $\gamma$-alumina powder contain intense peaks in the temperature range of $100-800{ }^{\circ} \mathrm{C}$. These peaks can be assigned to the $\mathrm{NH}_{3}$ desorbed from the acidic sites with medium to high strengths. Therefore, it can be concluded that the acid treated $\gamma$-alumina powder possesses strong surface acidic sites as compared to the $\gamma$-alumina powder. So the acid treatment improves the surface area and surface acidity of $\gamma-\mathrm{Al}_{2} \mathrm{O}_{3}$ Thus, the resulted $\gamma-\mathrm{Al}_{2} \mathrm{O}_{3}$ gave more lewis acidity and acid density. The x-ray diffraction (XRD) profile of the $\gamma-\mathrm{Al}_{2} \mathrm{O}_{3}$ confirms spinal lattice structure of the catalyst (Figure 3). The peaks indicate the amorphous nature of $\gamma-\mathrm{Al}_{2} \mathrm{O}_{3}$. The crystallite sizes calculated by using the Scherrer equation were found to be in the range of $4.5-5.5 \mathrm{~nm}$.

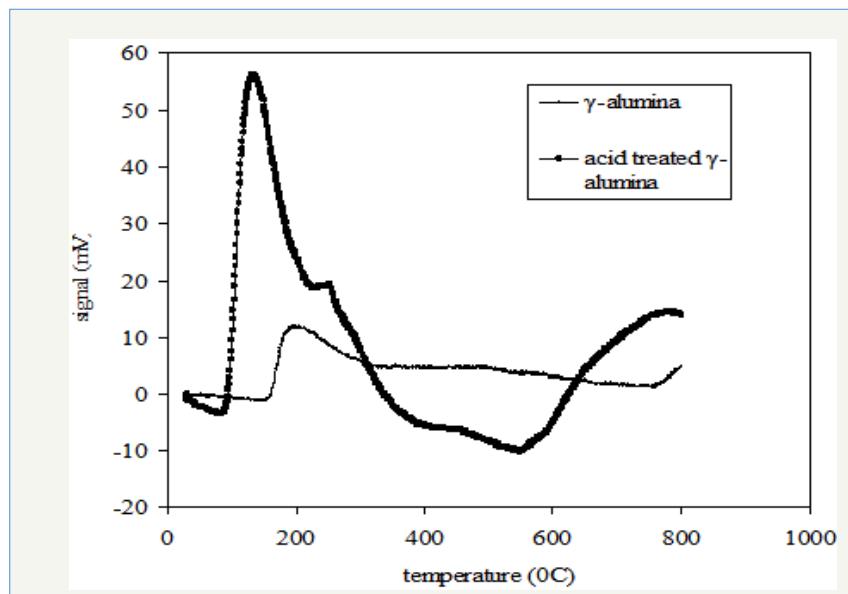

Figure 2: NH3-TPD profiles of $\gamma$-alumina and acid treated $\gamma$-alumina.

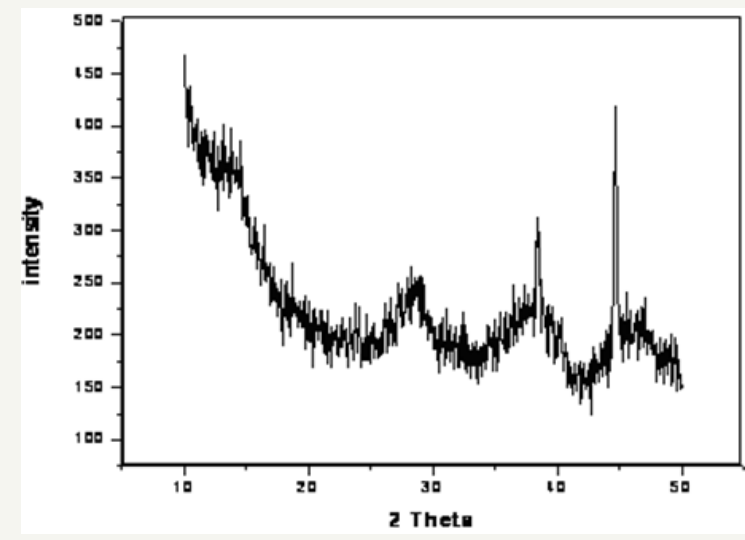

Figure 3: X-ray diffraction pattern of $\gamma$-alumina.

\section{Selection of solvent}

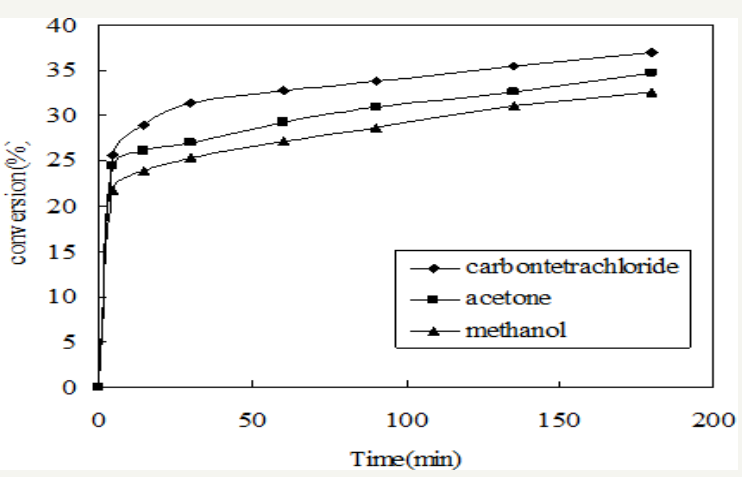

Figure 4: Effect of the solvents (Volume of phenol- $5 \mathrm{ml}$, volume of $\mathrm{CCl} 4-7.5 \mathrm{ml}$, HNO3 $(30 \%)-3 \mathrm{ml}$, weight of $\mathrm{\gamma}$-alumina-3gm, reaction time-3h, stirrer speed-400rpm). 
To select a suitable solvent the nitration of phenol was carried out at room temperature in presence of carbon tetrachloride $\left(\mathrm{CCl}_{4}\right)$, methanol and acetone using $\gamma$-alumina catalyst. The reaction was carried out using dilute nitric acid (30\%). The highest conversion of o-nitrophenol was obtained by using carbon tetrachloride as a solvent (Figure 4). The time required for completion of the reaction is also less in case of $\mathrm{CCl}_{4}$. Therefore $\mathrm{CCl}_{4}$ is selected as a suitable solvent for the further nitration study.

\section{Selection of catalyst}

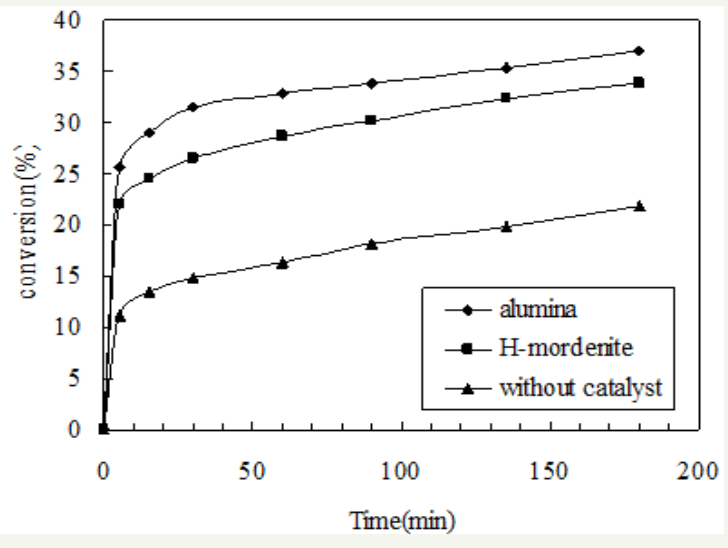

Figure 5: Effects of different catalysts.

The nitration of phenol was carried out separately in presence of $\gamma$-alumina and $\mathrm{H}$-mordenite. The reaction was carried out at room temperature for three hours. For this purpose $5 \mathrm{ml}$ phenol and $3 \mathrm{ml} \mathrm{HNO}_{3}(30 \%)$ were taken and $3 \mathrm{~g}$ of catalyst was added into it. The $\mathrm{CCl}_{4}(7.5 \mathrm{ml})$ was used as a solvent and the highest yield of o-nitro phenol was obtained using alumina catalyst. The yield of o-nitro phenol was decreased when the catalyst was changed from alumina to $\mathrm{H}$-mordenite. The conversion of o-nitro phenol was low in this case because of less number of acid sites as well as porosity of $\mathrm{H}$-mordenite. The reaction was also carried out in absence of catalyst and the conversion was further decreased, resulting nearly equal amount of ortho- and para- isomers. The effects are shown in Figure 5.

\section{Effect of $\mathrm{HCl}$ treatment on alumina catalyst}

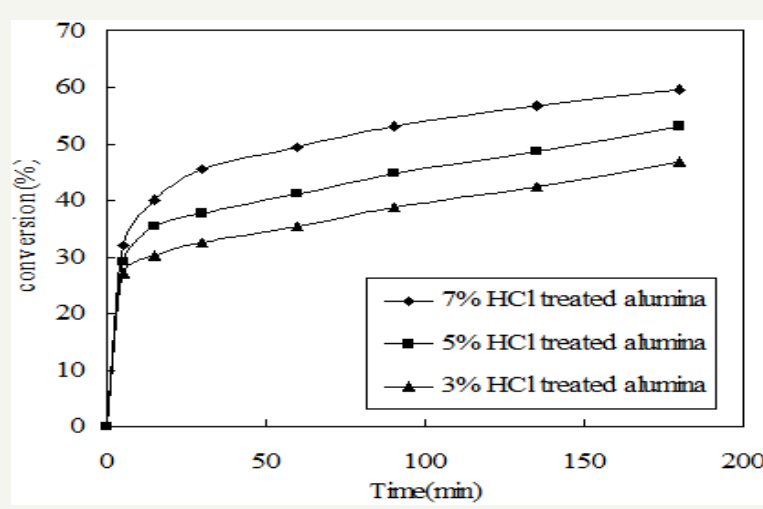

Figure 6: Effect of $\mathrm{HCl}$ treatment on alumina catalyst.
The catalytic activity of alumina was enhanced by treating it with different percentage of hydrochloric acid. The catalytic activity is increased with increase in surface acidity and was found to be in the following order $7 \% \mathrm{HCl}$ treated alumina $>5 \% \mathrm{HCl}$ treated alumina $>3 \% \mathrm{HCl}$ treated alumina. The effects are shown in Figure 6 . The other reaction conditions such as type of solvent, amount of reactants, reaction time and temperature were remain same as before.

\section{Effect of the reaction time}

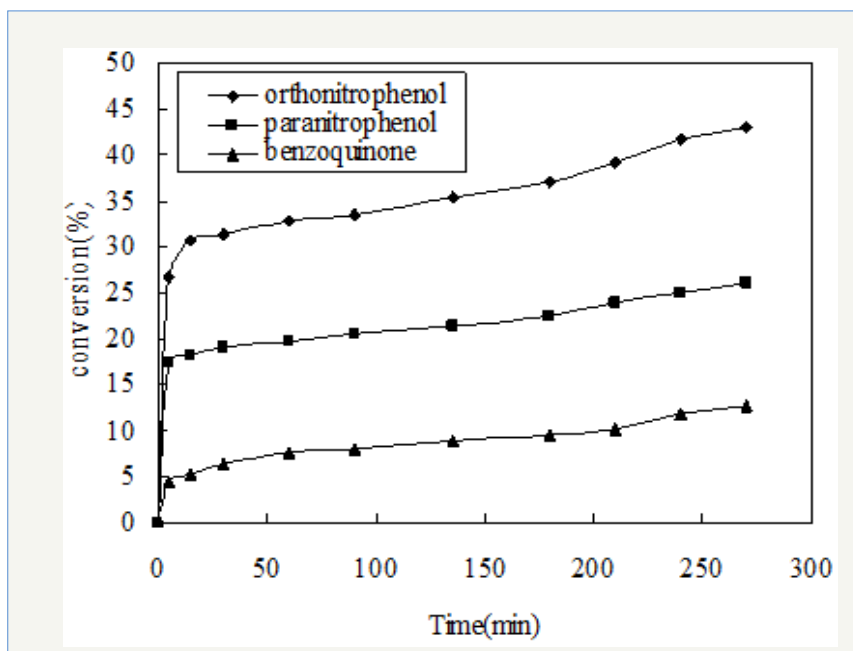

Figure 7: Effect of reaction time.

The nitration of phenol was carried out by varying reaction time in the presence of alumina catalyst (3gm) at room temperature. The reaction time was varied from $5-270 \mathrm{~min}$. In this case phenol $(5 \mathrm{ml})$ and dilute nitric acid $(3 \mathrm{ml})$ were used as reactants and $\mathrm{CCl}_{4}$ $(7.5 \mathrm{ml})$ was used as a solvent. The results indicate that the yield of o-nitro phenol increases with increasing reaction time because more number of nitronium ions are formed as the time proceeds, resulting higher conversion of phenol (Figure 7). Therefore the maximum yield of o-nitrophenol was obtained at $4.5 \mathrm{~h}$.

\section{Effect of weight of the catalysts}

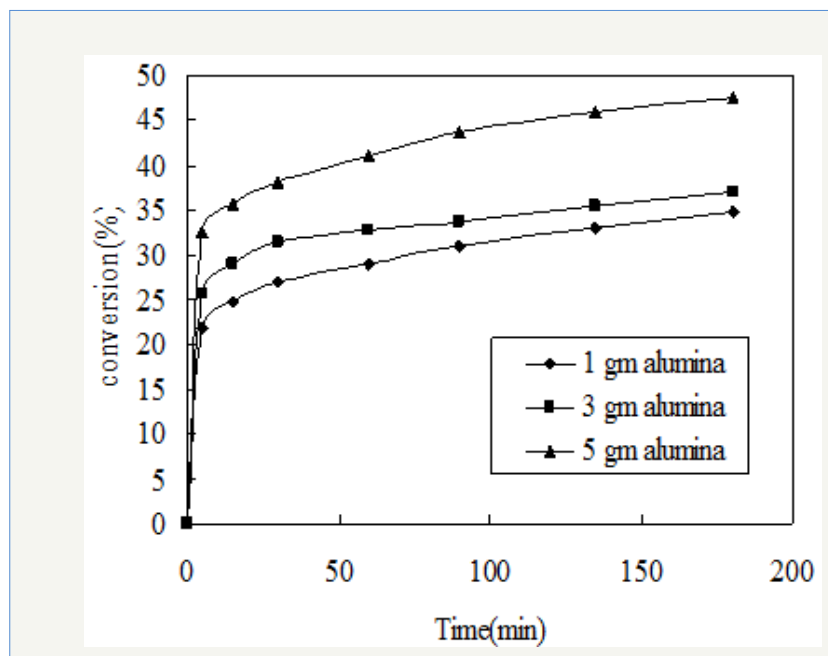

Figure 8: Effect of catalyst weight. 
The conversion of o-nitrophenol also depends on the weight of catalyst. The nitration of phenol was carried out using dilute nitric acid $(3 \mathrm{ml})$ using different weight of alumina catalyst at room temperature. The effects are shown in Figure 8. The percent conversion of phenol increases with increasing weight of catalyst due to availability of more surface area. The reaction speed is also enhanced with increasing catalyst dose. Therefore the highest conversion was obtained using $5 \mathrm{gm}$ of catalyst.

\section{Effect of reactant concentration}

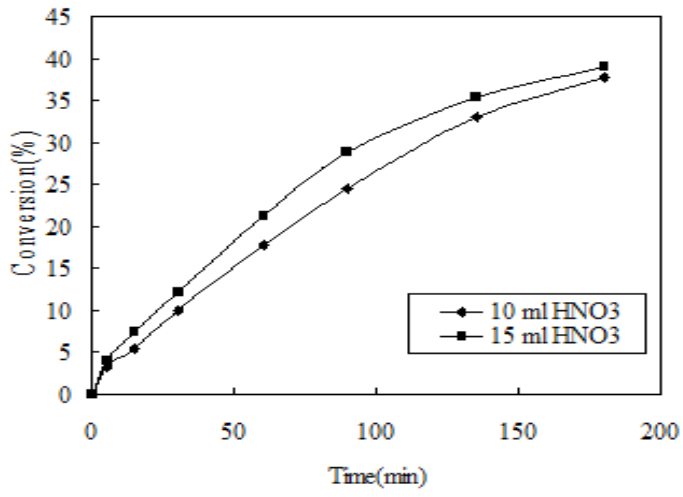

(a)

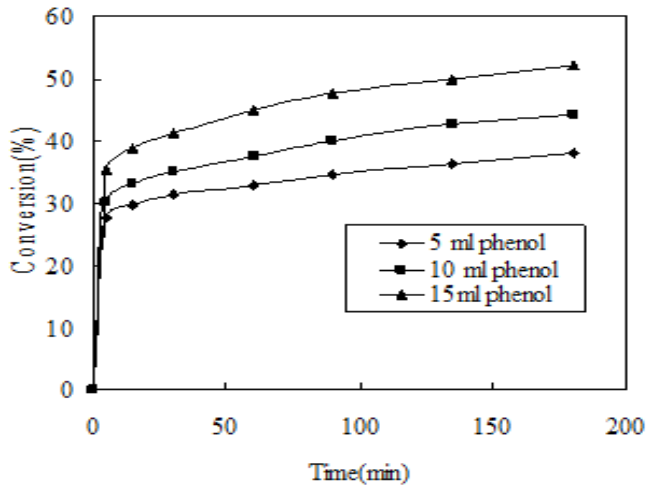

(b)

Figure 9: Effect of reactant concentration (Volume of $\mathrm{CCl}_{4}-7.5 \mathrm{ml}, \mathrm{HNO}_{3}(30 \%)-3 \mathrm{ml}$, reaction time $=3 \mathrm{~h}$, reaction temperature-room temperature and stirrer speed-400rpm).

The effect of concentration of phenol and nitric acid is studied on the rate of reaction and the effects are shown in Figure 9. As the concentration of reactants (phenol and nitric acid) is increased, the rate of reaction also increases.

\section{Kinetic Study}

Table 2

\begin{tabular}{|c|c|c|c|}
\hline $\begin{array}{c}\text { Temperature } \\
\text { (0K), T }\end{array}$ & $\left.\mathbf{1 / T} \mathbf{~ ( K}^{-\mathbf{1}}\right)$ & $\begin{array}{c}\mathbf{k}\left(\mathbf{L ~ m o l e}^{-\mathbf{1}}\right. \\
\left.\mathbf{s e c}^{-1}\right)\end{array}$ & $\mathbf{~} \mathbf{k}$ \\
\hline 303 & 0.0033 & 10.83333 & 2.382628 \\
\hline 318 & 0.003145 & 13.91667 & 2.633087 \\
\hline 333 & 0.003003 & 16 & 2.772589 \\
\hline 353 & 0.002833 & 20.75 & 3.032546 \\
\hline
\end{tabular}

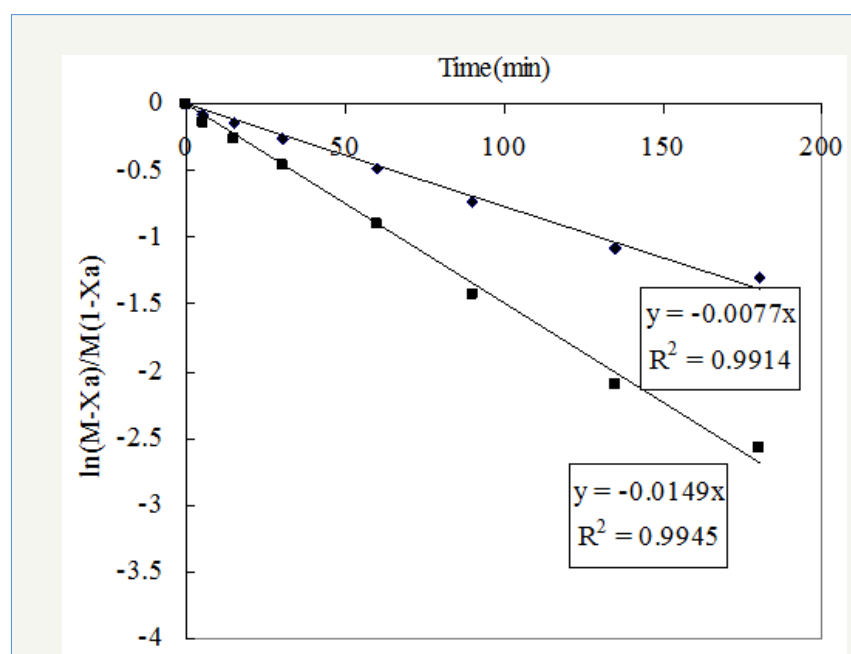

Figure 10: Second order model fit.

The pseudo second order rate expressions were taken into consideration to correlate the kinetic data. Here the second order rate model (Equation 6) was fitted with data of nitration reaction (Figure 10). The kinetic study was carried out by varying the amount of nitric acid from $10-15 \mathrm{ml}$. The other reaction conditions are kept as before for both the cases. It was observed that the kinetics of nitration for both the cases obeys the pseudo second order rate equation. The values of kinetic parameters are shown in Table 2. It can be seen from the following figures that for two different volume of nitric acid ( 10 and $15 \mathrm{ml}$ ) the values of rate constant is 5.839 and 6.353L mole $\mathrm{Lec}^{-1}$ respectively.

\section{Study of the Arrhenius Equation}

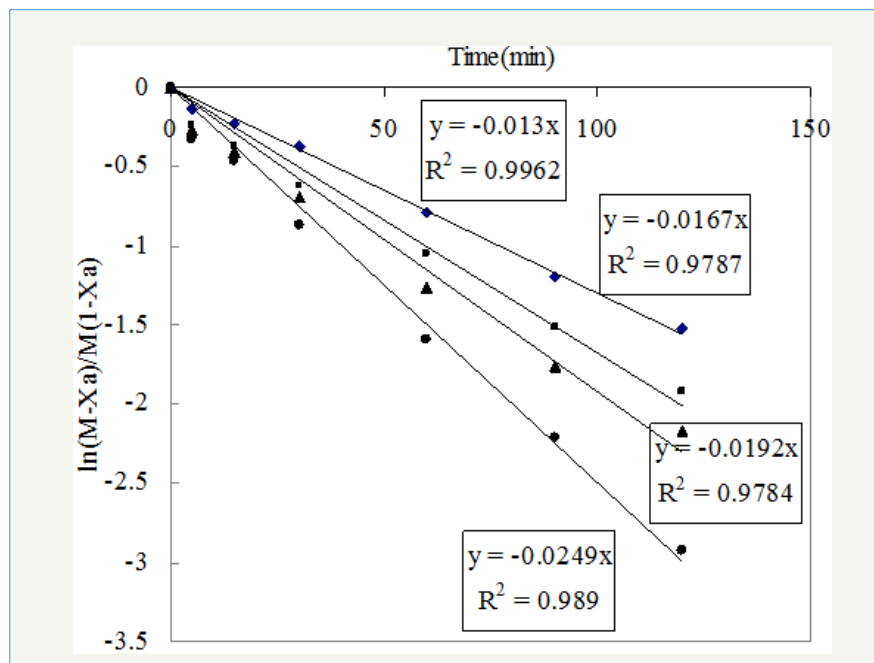

Figure 11: Effect of temperature of the reaction.

The kinetic study was also performed by varying the reaction temperature from $30-80{ }^{\circ} \mathrm{C}$ to investigate the Arrhenius Equation. The values of different parameters such as amount of phenol, 
amount of solvent, weight of catalyst and the reaction time were maintained as before throught out the reaction. Fifteen ml of nitric acid was taken in this case. The values of rate constant at different temperature are obtained from Figure 11. The activation energy is calculated from the slop of Figure 12 and it is found to be $11.272 \mathrm{KJ} /$ mol.

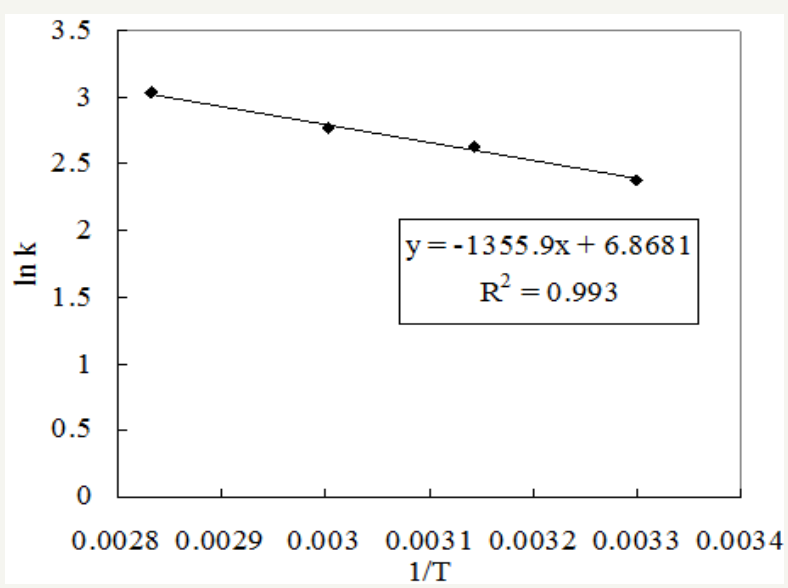

Figure 12: Temperature dependency of a reaction according to Arrhenius law.

\section{Conclusion}

Phenol is selectively nitrated to ortho-nitrophenol in high yields with dilute nitric acid in carbon tetrachloride solvent over gamma-alumina catalyst. The gamma-alumina catalyst could be easily separated from the reaction mixture by filtration for recycle and the workup procedure is simple as compared to the other conventional process. The region selectively nitration of phenol using dilute nitric acid over solid acid catalyst without any use of acetic anhydride/acyl nitrate, metal nitrates or sulfuric acid is a comparatively clean and environmental friendly process.

\section{References}

1. Sharda P Dagade, Vijay S Kadam, Mohan K Dongare (2002) Regioselective nitration of phenol over solid acid catalysts. Catalysis Communications 3(2002): 67-70.

2. Majid M Heravi, Tina Benmorad, Khadijeh Bakhtiari, Fatemeh $\mathrm{F}$ Bamoharram, Hossein $\mathrm{H}$ Oskooie (2007) $\mathrm{H}_{3}+\mathrm{PMo}_{12-\mathrm{x}} \mathrm{V}_{\mathrm{x}} \mathrm{O}_{40}$

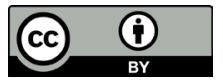

Creative Commons Attribution 4.0

International License

For possible submission use the below is the URL

Submit Article (heteropolyacids)-catalyzed regioselective nitration of phenol to o-nitrophenol in heterogeneous system. Journal of Molecular Catalysis A: Chemical 264(1-2): 318-321.

3. T Esakkidurai, K Pitchumani (2002) Zeolite-mediated regioselective nitration of phenol in solid state. Journal of Molecular Catalysis A: Chemical 185(1-2): 305-309.

4. Sujata Mallick, KM Parida (2007) Selective nitration of phenol over silicotungstic acid supported zirconia. Catalysis Communications 8(10): 1487-1492.

5. Nitin S Nandurkar, Mayur J Bhanushali, Sachin R Jagtap, Bhalchandra M Bhanage (2007) Ultrasound promoted regioselective nitration of phenols using dilute nitric acid in the presence of phase transfer catalyst. Ultrason Sonochem 14(1): 41-45.

6. Ashutosh V Joshi, Mubeen Baidoosi, Sudip Mukhopadhyay, Yoel Sasson (2003) Nitration of phenol and substituted phenols with dilute nitric acid using phase-transfer catalysts. Org Proc Res Dev 7(1): 95-97.

7. KR Sunajadevi, S Sugunan (2005) Sulfated titania mediated regioselective nitration of phenol in solid state. Catalysis Communications 6(9): 611616.

8. Mathew R Heal, Mark AJ Harrison, J Neil Cape (2007) Aqueous phase nitration of phenol by $\mathrm{N}_{2} \mathrm{O}_{5}$ and $\mathrm{ClNO}_{2}$. Atmospheric Environment 41(17): 3515-3520.

9. V Anuradha, PV Srinivas, P Aparna, J Madhusudana Rao (2006) p-Toluenesulfonic acid catalyzed regiospecific nitration of phenols with metal nitrates. Tetrahedron Letters 47(28): 4933-4935.

10. M Arshadi, M Ghiaci, A Gil (2010) Nitration of phenol over a ZSM-5 zeolite. Ind Eng Chem Res 49(12): 5504-5510.

11. KR Sunajadevi, S Sugunan (2006) Selective nitration of phenol over sulfated titania systems prepared via sol-gel route. Materials Letters 60(29-30): 3813-3817.

12. AS Khder, AI Ahmed (2009) Selective nitration of phenol over nanosized tungsten oxide supported on sulfated $\mathrm{SnO}_{2}$ as a solid acid catalyst. Applied Catalysis A: General 354(1-2): 153-160.

13. Firouzeh Nemati, Hossein Kiani (2010) $\mathrm{Zn}\left(\mathrm{NO}_{3}\right)_{2} \cdot 6 \mathrm{H}_{2} \mathrm{O} / 2,4,6$-trichloro1,3,5-triazine (TCT) a mild and selective system for nitration of phenols. Chinese Chemical Letters 21(4): 403-406.

14. R Rajagopal, KV Srinivasan (2003) Ultrasound promoted para-selective nitration of phenols in ionic liquid. Ultrason Sonochem 10(1): 41-43.

15. SM Kemdeo, VS Sapkal, GN Chaudhari (2010) $\mathrm{TiO}_{2}-\mathrm{SiO}_{2}$ mixed oxide supported $\mathrm{MoO}_{3}$ catalyst: Physicochemical characterization and activities in nitration of phenol. Journal of Molecular Catalysis A: Chemical 323(1-2): 70-77.

\section{Your subsequent submission with Crimson Publishers will attain the below benefits}

- High-level peer review and editorial services

- Freely accessible online immediately upon publication

- Authors retain the copyright to their work

- Licensing it under a Creative Commons license

- Visibility through different online platforms

- Global attainment for your research

- Article availability in different formats (Pdf, E-pub, Full Text)

- Endless customer service

- Reasonable Membership services

- Reprints availability upon request

- One step article tracking system 